\title{
Review on techniques of automatic solid waste separation in domestic applications
}

\author{
Luisa María Alcaraz-Londoño, Luis Felipe Ortiz-Clavijo, Carlos Julián Gallego Duque, Sergio \\ Armando Gutiérrez Betancur \\ Faculty of Engineering, Universidad Autónoma Latinoamericana, Medellín, Antioquia, Colombia
}

\begin{abstract}
Article Info
\section{Article history:}

Received Aug 30, 2021

Revised Dec 10, 2021

Accepted Dec 24, 2021

\section{Keywords:}

Automatic separation Recycling of household

Review

Solid waste

Techniques

ABSTRACT

The accelerated modern day urban development is accompanied by an increasing production of solid waste. While managing solid waste on an industrial scale presents different technological challenges, managing household waste requires decentralized solutions dealing with the associated logistic and technical difficulties. In this review, we identify the research trends on household waste recycling by providing a brief description of the main technologies, and the traditional formats commonly used for solid waste (SW) separation. We identify two main threads: the SW management systems within a smart city framework and the design of domestic waste classification systems based on intelligent mechanisms tailored to user psychology. Among the main conclusions, we verify a growing interest in the subject of SW separation in domestic applications, mainly through solutions based on automation and internet of things (IoT). Also, we detected a increasing interest in the analysis of psychological aspects and in citizen education in relation to the importance of recycling, since without this notion the success of proposed solutions might be limited.
\end{abstract}

This is an open access article under the CC BY-SA license.

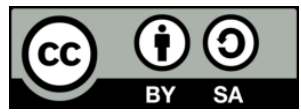

\section{Corresponding Author:}

Luisa María Alcaraz-Londoño

Faculty of Engineering, Universidad Autónoma Latinoamericana

Cra. 55a \# 49-51, Medellín, Antioquia, Colombia

Email: luisa.alcaraz5088@unaula.edu.co

\section{INTRODUCTION}

Due to economic growth and urbanization, more polymer waste is generated in industry and households nowadays [1]. In literature, there is a noticeable spike in scientific works aiming at introducing new solutions for recycling processes since 2003 [2]. Recycling of household wastes has been widely considered as a key factor for reducing the pollution caused by municipal solid waste and promoting sustainable development [3]. Solid waste (SW) separation techniques refer to modifying a body, suppressing local consistency, and allowing the selection of its unique components [4]. Such processes play an important role in various fields, especially in industry and in the reuse of SW.

The selection and classification of waste are some of the main challenges [5]. Manual sorting is considered expensive and inefficient when large amounts of SW are involved. Literature reports automatic SW separation approaches based on techniques such as dense separation [1], column flotation [6], image recognition [7], magnetic separation [8], Foucault streams [9], sensors [10], robotics, and artificial intelligence [11], [12]. Automatic separation techniques are also applied in different industries for recycling processes in solid waste deposits [13]. However, the implementation of this type of separation in the domestic context is not recurrent. If implemented, it would represent a great advance in terms of waste use by decentralizing the whole recycling process [14]. To the best of our knowledge, an up-to-date systematic 
review of the domestic SW management techniques has yet to be done. This work identifies, reviews, and compares recent SW separation techniques currently implemented for domestic applications.

The remaining of this paper is organized as: section 2 describes the methodology used to perform the review. This includes the search strategy used, the searched databases, and the inclusion and exclusion criteria. Results are presented afterwards in section 3, revealing the main study trends, the institutions with the highest number of publications, and the countries with the largest participation in the generation of literature in this field. Finally, in section 4 we present the conclusions, highlighting elements of the current state-of-the-art research in this topic.

\section{RESEARCH METHOD}

\subsection{Review structure}

In this section we describe the basic elements of our review process, whose goal is identifying trends and fields of research related to SW separation techniques and their application at the domestic level. We used the preferred reporting items for systematic reviews and meta-analysis (PRISMA) guidelines to structure this review [15]. We selected several specialized databases on engineering and electronic applications. Articles published between 1968 and July 30th, 2021, were included from the Elsevier (SCOPUS), and IEEE databases. Our seach strategy consisted in querying the respective databases by creating a search equation through the following search strings applied to the title, abstract and keywords fields: "SW separation", "automatic SW techniques", "domestic SW", "separation and waste domestic".

\subsection{Data collection}

The following inclusion criteria were defined: i) papers published in peer-reviewed journals and ii) written in English, as shown in Figure 1.

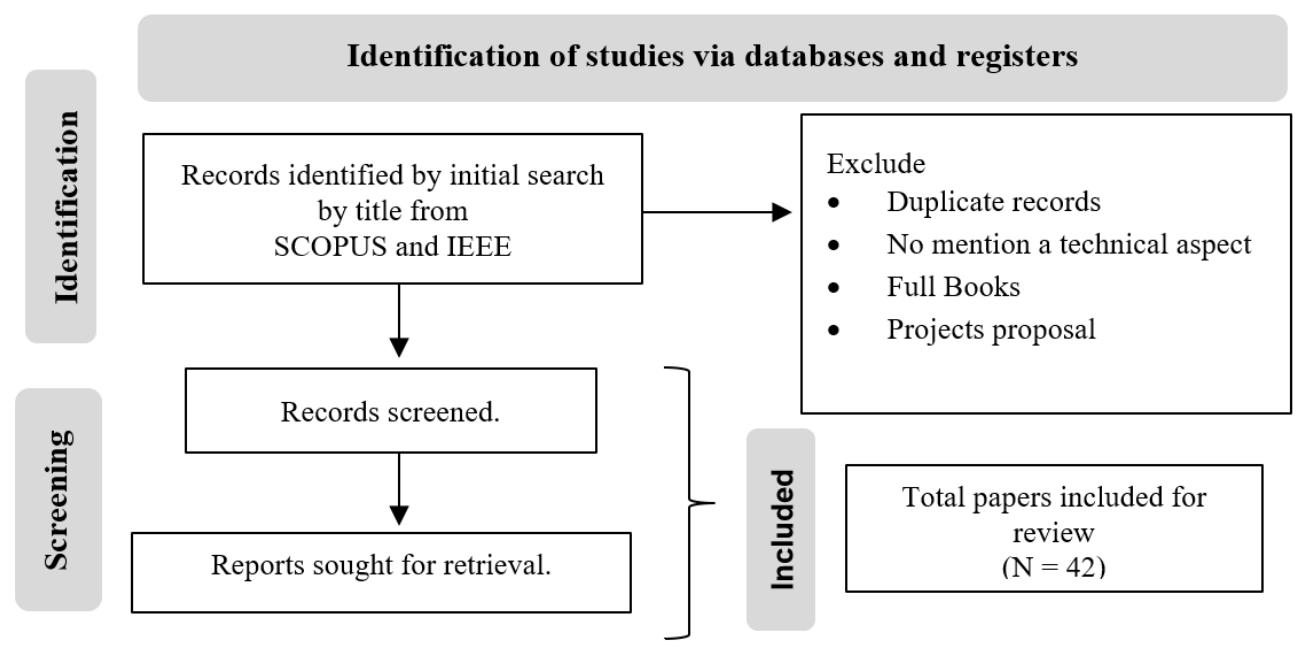

Figure 1. PRISMA diagram for paper screening [15]

\section{RESULTS AND DISCUSSION}

\subsection{Current state of scientific production in the area}

In 1968, scientific production on the subject of waste separation began. Figures 2 and 3 show the number of publications by country, which has increased significantly since 2003. Table 1 lists papers that have either developed theoretical models or have provided research examples for the later studies on SW domestic applications. Solutions reported in the literature are mainly focused on automatic SW models and applications seeking to optimize the classification processes, and the development at the level of transport and monitoring of collection processes. 
Documents by year

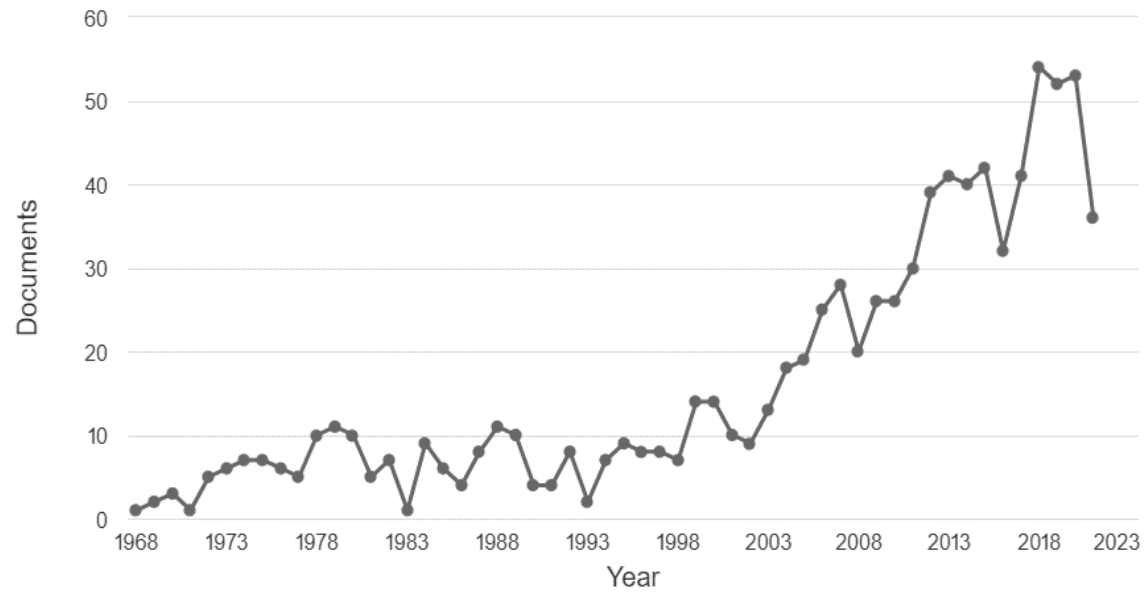

Figure 2. Scientific production on SCOPUS for waste separation

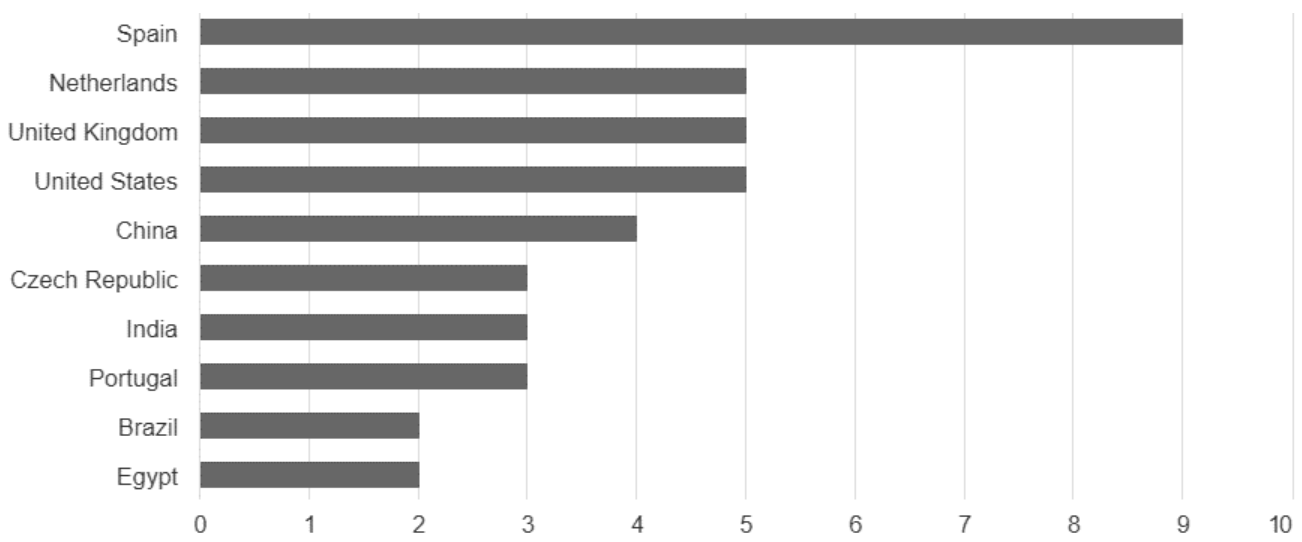

Figure 3. Scientific production by country

Table 1. Included studies: SW domestic applications by category

\begin{tabular}{|c|c|c|}
\hline Authors & Category & Description \\
\hline $\begin{array}{l}\text { Cruz et al., (2015) [19] } \\
\text { Siddappaji et al., (2016) [20] } \\
\text { Chun-lin et al., (2019) [21] } \\
\text { Das et al., (2021) [22] }\end{array}$ & $\begin{array}{l}\text { - Waste collection and } \\
\text { monitoring } \\
\text { - Transportation } \\
\text { applications }\end{array}$ & $\begin{array}{l}\text { Solutions are proposed based on IoT, automation and adaptation of } \\
\text { containers for use at the domestic level. These are oriented to waste } \\
\text { collection, monitoring, and transport systems. }\end{array}$ \\
\hline $\begin{array}{l}\text { Liu et al., (2020) [24] } \\
\text { Hassan et al., (2018) [25] } \\
\text { Rajkamal et al., (2014) [26] }\end{array}$ & $\begin{array}{l}\text { Domestic waste } \\
\text { classification }\end{array}$ & $\begin{array}{l}\text { Improves the initial conditions of SW domestically, and } \\
\text { consequently optimizes the successive processes: collection, } \\
\text { transport, classification, and use. }\end{array}$ \\
\hline
\end{tabular}

\subsection{Main studies}

Literature reported that the main problem faced by waste sorting is the lack of a suitable garbage collection device that can reasonably classify and recycle waste [24]. Some authors have suggested the solutions; i) multi-stage separation processes based on cyclones for waste plastic films using downward spiral motion, also known as external swirling airflow. Particulate impurities are propelled to the outer wall by the centrifugal force generated by the airflow, and then lose inertia due to gravity [27]; ii) automatic methods 
based on systems with eco-design applications. These approaches to product quality assessment integrate environmental aspects as they focus on complying with ecological standards at an early stage of design, enabling recycling of items after their useful life [16]; iii) multi classification categorial algorithms. The proposed algorithms identify four major categories and 10 subclasses of domestic garbage. These two classification tasks are related to each other; implemented joint loss function is helpful to improve the accuracy of garbage recognition [17].

Other solutions explore problems from collection to classification through mixed integer optimization models to collect recyclable waste [19]. Techniques employed include RFID and smart systems (GSM and GIS) [20], garbage collection and transportation network systems based on Voronoi graph theory [21], grouped and classified garbage maintenance systems for mobile devices [23], automatic detection and classification systems based on multi-model cascaded convolutional neural networks [25], monitoring system driven by internet of things (IoT) [25], [28], and IoT-based SW segregation based on relative humidity values [22].

\subsection{Trends}

SW management systems within a smart city framework. In literature, automation models are proposed for the classification of SW, finding an element in common corresponding to the intention of developing integral management systems [22], [29], [30]. Application design tailored to user psychology. This trend relates to the behavior and psychology of users. Several authors stressed the need to adopt good environmental practices by raising scientific awareness and normalizing habits of waste classification [31]. In Figure 4, the authors' keywords are grouped into one major cluster (185 items) and two relatively minor clusters (181 and 180 items) representing household waste research, wastewater treatment, and the separation phase respectively.

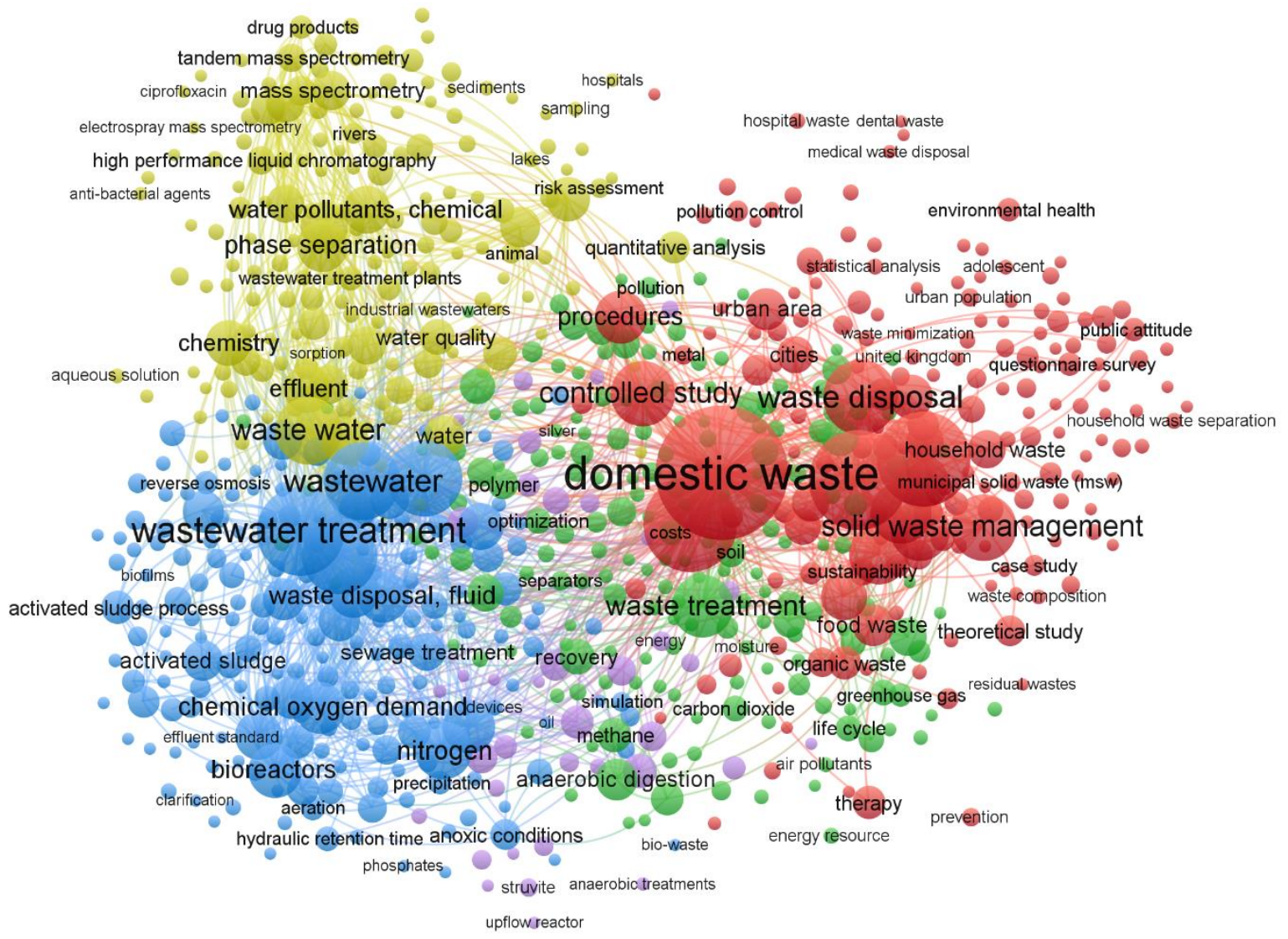

Figure 4. Cluster analysis of the authors' keywords

\section{CONCLUSION}

This work aimed at providing a review of the techniques of automatic separation of solid waste in domestic applications. The analysis of scientific productivity shows the research field of automatic solid waste separation techniques in domestic applications is still growing as the annual production from 2014 to 2020 has 
yet to slow down. We could see a growing interest in the topic of SW separation in domestic applications, mainly through solutions based on automation and IoT. This was mentioned by Garcés-Gómez and colleagues back in 2013, as they highlighted the use of IoT in environmental applications. Research guided by user psychology has been gaining prominence. As the mental processes of an individual are related to their social and behavioral aspects, this could have a great impact to encourage recycling on the domestic level.

\section{ACKNOWLEDGEMENTS}

This work was funded by the Colombia Científica-Alianza EFI Research Program, code 60185 and contract number FP44842-220-2018. It was funded by The World Bank through the call Scientific Ecosystems, managed by the Colombian Ministry of Science, Technology, and Innovation.

\section{REFERENCES}

[1] W. O. M.Quelal, "Estudio de las diferentes técnicas de separación durante el proceso de reciclado de plásticos," Sep. 2019.

[2] B. Raj, J. Kumar, and V. V. L. Kanta Rao, "Plastic/packaging waste separation from MSW and its conversion and used as valueadded products in different applications: An eco-sustainable approach," Indian Journal of Engineering and Materials Sciences, vol. 27, no. 2, pp. 193-208, 2020.

[3] K. Shi, Y. Zhou, and Z. Zhang, "Mapping the research trends of household waste recycling: A bibliometric analysis," Sustainability (Switzerland), vol. 13, no. 11, 2021, doi: 10.3390/su13116029.

[4] C. J. Geankoplis, Procesos de transporte y principios de procesos de separación. 2006.

[5] R. Heidari, R. Yazdanparast, and A. Jabbarzadeh, "Sustainable design of a municipal solid waste management system considering waste separators: A real-world application," Sustainable Cities and Society, vol. 47, p. 101457, 2019, doi: https://doi.org/10.1016/j.scs.2019.101457.

[6] E. Agante, I. Rodrigues, and T. Carvalho, "Separation of PET from PVC by column flotation," 2006, vol. 6, pp. 331-340

[7] M. L. Kazaryan, A. A. Richter, and M. A. Shakhramanian, "Method of automatic detecting the components of waste disposal objects by space images," Bulletin of the Tomsk Polytechnic University, Geo Assets Engineering, vol. 328, no. 3, pp. 46-53, 2017.

[8] P. Zhao, J. Xie, F. Gu, N. Sharmin, P. Hall, and J. Fu, "Separation of mixed waste plastics via magnetic levitation," Waste Management, vol. 76, pp. 46-54, 2018, doi: https://doi.org/10.1016/j.wasman.2018.02.051.

[9] J. R. Nagel, "An analytic model for eddy current separation," Minerals Engineering, vol. 127, pp. 277-285, 2018, doi: 10.1016/j.mineng.2018.08.025.

[10] J.-W. Lu, N.-B. Chang, F. Zhu, J. Hai, and L. Liao, "Smart and green urban solid waste collection system for differentiated collection with integrated sensor networks," in 2018 IEEE 15th international conference on networking, sensing and control (ICNSC), 2018, pp. 1-5. doi: 10.1109/ICNSC.2018.8361307.

[11] E. Alvarez-de-los-Mozos and A. Renteria, "Collaborative Robots in e-waste Management," Procedia Manufacturing, vol. 11, pp. 55-62, 2017, doi: https://doi.org/10.1016/j.promfg.2017.07.133.

[12] H. Wilts, B. R. Garcia, R. G. Garlito, L. S. Gómez, and E. G. Prieto, "Artificial Intelligence in the Sorting of Municipal Waste as an Enabler of the Circular Economy," Resources, vol. 10, no. 4. 2021. doi: 10.3390/resources10040028.

[13] S. H. Yusoff, S. Mahat, N. S. Midi, S. Y. Mohamad, and S. A. Zaini, "Classification of different types of metal from recyclable household waste for automatic waste separation system," Bulletin of Electrical Engineering and Informatics, vol. 8, no. 2, pp. 488-498, 2019, doi: 10.11591/eei.v8i2.1488.

[14] D. Knickmeyer, "Social factors influencing household waste separation: A literature review on good practices to improve the recycling performance of urban areas," Journal of Cleaner Production, vol. 245, p. 118605, 2020, doi: https://doi.org/10.1016/j.jclepro.2019.118605.

[15] M. J. Page et al., "PRISMA 2020 explanation and elaboration: updated guidance and exemplars for reporting systematic reviews," bmj, vol. 372, 2021 .

[16] R. Wichniarek, D. Grajewski, J. Diakun, E. Dostatni, and A. Karwasz, "Automatization of the ecodesign process of small household appliances based on CAD 3D system," Tehnicki Vjesnik, vol. 25, no. 1, pp. 18-25, 2018, doi: 10.17559/TV20160602135201.

[17] M. Zeng, X. Lu, W. Xu, T. Zhou, and Y. Liu, "PublicGarbageNet: A Deep Learning Framework for Public Garbage Classification," in Chinese Control Conference, CCC, 2020, vol. 2020-July, pp. 7200-7205. doi: 10.23919/CCC50068.2020.9189561.

[18] J. Li et al., "Automatic Detection and Classification System of Domestic Waste via Multi-model Cascaded Convolutional Neural Network," IEEE Transactions on Industrial Informatics, p. 1, 2021, doi: 10.1109/TII.2021.3085669.

[19] Y. X. D. Cruz, J. A. P. Chirva, and E. R. L. Santana, "A mixed integer optimization model to design a selective collection routing problem for domestic solid waste," in 2015 Workshop on Engineering Applications - International Congress on Engineering (WEA), 2015, pp. 1-5. doi: 10.1109/WEA.2015.7370127

[20] Siddappaji, K. Sujatha, and R. C. Radha, "Technologies for segregation and management of solid waste: A review," in 2016 International Conference on Emerging Trends in Engineering, Technology and Science (ICETETS), 2016, pp. 1-4. doi: 10.1109/ICETETS.2016.7603046.

[21] X. Chun-Lin, L. Shuo, and S. Feng-Wu, "Reconfiguration of Garbage Collection and Transportation Network System Based on Voronoi Graph Theory: A Simulation Case of Beijing Region," in 2019 International Conference on Industrial Engineering and Systems Management (IESM), 2019, pp. 1-6. doi: 10.1109/IESM45758.2019.8948117.

[22] A. Das, A. Shukla, R. Manjunatha, and E. A. Lodhi, "IoT based Solid Waste Segregation using Relative Humidity Values," in 2021 Third International Conference on Intelligent Communication Technologies and Virtual Mobile Networks (ICICV), 2021, pp. 312-319. doi: 10.1109/ICICV50876.2021.9388611.

[23] N. Sivakumar, A. R. Kunwar, S. K. Patel, S. Kumar, and S. P. Mala, "Design and development of an automatic clustered, assorted trash segregation system," in 2016 IEEE International Conference on Recent Trends in Electronics, Information \& Communication Technology (RTEICT), 2016, pp. 409-413. doi: 10.1109/RTEICT.2016.7807852. 
[24] J. Wang et al., "A simple garbage bin design for garbage classification and recycling," in Proceedings - 2020 3rd World Conference on Mechanical Engineering and Intelligent Manufacturing, WCMEIM 2020, 2020, pp. 819-822. doi: 10.1109/WCMEIM52463.2020.00175.

[25] H. Hassan, F. Saad, N. Fazlin, and A. Aziz, "Waste Monitoring System based on Internet-of-Thing (IoT)," in 2018 IEEE Conference on Systems, Process and Control (ICSPC), 2018, pp. 187-192. doi: 10.1109/SPC.2018.8704142.

[26] R. Rajkamal, V. Anitha, P. G. Nayaki, K. Ramya, and E. Kayalvizhi, "A novel approach for waste segregation at source level for effective generation of electricity - GREENBIN," in 2014 International Conference on Science Engineering and Management Research (ICSEMR), 2014, pp. 1-4. doi: 10.1109/ICSEMR.2014.7043540.

[27] Q. S. Zhang, Z. S. Zhang, X. H. Yang, Z. Yang, and L. Y. Yang, "Simulation and optimization design of cyclone separator for waste plastic film," in Journal of Physics: Conference Series, 2021, vol. 1948, no. 1. doi: 10.1088/1742-6596/1948/1/012170.

[28] T. Bhuvaneswari, J. Hossen, NurAsyiqinbt. Amir Hamzah, P. Velrajkumar, and O. Hong Jack, "Internet of things (IoT) based smart garbage monitoring system," Indonesian Journal of Electrical Engineering and Computer Science, vol. 20, no. 2, p. 736, Nov. 2020, doi: 10.11591/ijeecs.v20.i2.pp736-743.

[29] R. Ramly, A. A. B. Sajak, and M. Rashid, "IoT recycle management system to support green city initiatives," Indonesian Journal of Electrical Engineering and Computer Science, vol. 15, no. 2, p. 1037, Aug. 2019, doi: 10.11591/ijeecs.v15.i2.pp1037-1045.

[30] A. A. I. Shah, S. S. M. Fauzi, R. A. J. M. Gining, T. R. Razak, M. N. F. Jamaluddin, and R. Maskat, "A review of IoT-based smart waste level monitoring system for smart cities," Indonesian Journal of Electrical Engineering and Computer Science, vol. 21, no. 1, p. 450, Jan. 2021, doi: 10.11591/ijeecs.v21.i1.pp450-456.

[31] V. Henao-Céspedes, G. Y. Florez, and Y. A. Garcés-Gómez, "The internet of things in high andean wetland monitoring, historical review approach,” Bulletin of Electrical Engineering and Informatics, vol. 10, no. 3, pp. 1572-1579, 2021.

\section{BIOGRAPHIES OF AUTHORS}
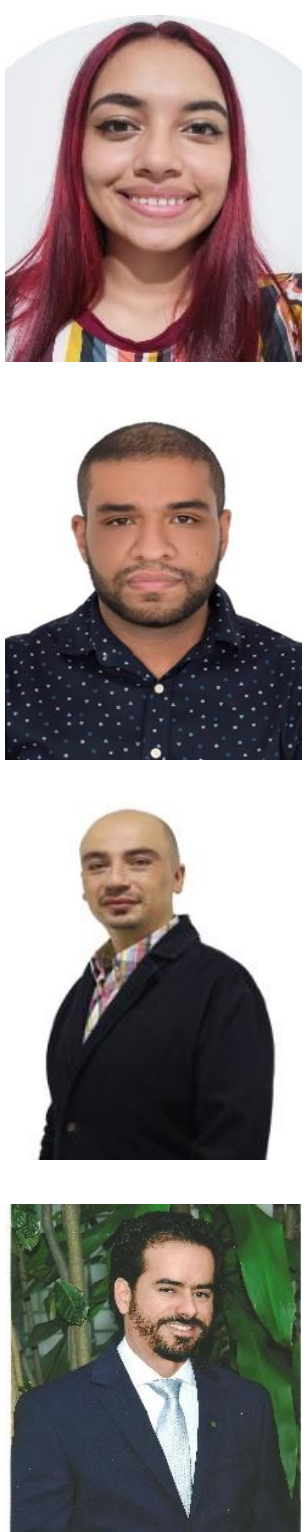

Luisa María Alcaraz-Londoño (D) SS $\mathrm{SC}$ is a junior frontend and backend developer. Currently BS degree Student in Informatics Engineering at Universidad Autónoma Latinoamericana, Medellín, Colombia. She can be contacted at email: luisa.alcaraz5088@unaula.edu.co.

Luis Felipe Ortiz-Clavijo (D) 81 SC P earned his B.S. degree in Industrial Engineering from Universidad Autónoma Latinoamericana. He is currently Master in data science (Engineering: Analytics) Student at Universidad Nacional de Colombia and Junior Research Fellow at Universidad Autónoma Latinoamericana, Medellín, Colombia. He can be contacted at email: luisfelipe.ortiz@unaula.edu.co.

Carlos Julián Gállego Duque (D) SD SC P obtained his Master in Automation and Industrial Control, earned his B.S. degree in Instrumentation and Control Engineering from Politécnico Colombiano Jaime Isaza Cadavid. He is currently Lecturer at Universidad Autónoma Latinoamericana, Medellín, Colombia. $\mathrm{He}$ can be contacted at email: carlosjulian.gallego@unaula.edu.co.

Sergio Armando Gutiérrez Betancur (D) 8f SC P is a reseacher lecturer at Universidad Autónoma Latinoamericana (UNAULA). Formerly, was full time lecturer and researcher at Universidad de Medellin (UDEM). Obtained his PhD in Computer Science in 2018 at Universidad Nacional de Colombia-Sede Medellín (UNAL). He can be contacted at email: sergio.gutierrezbe@unaula.edu.co. 